\title{
POLÍTICAS PÚBLICAS DE LEITURA E BIBLIOTECA ESCOLAR: análise da materialização em Anhumas / São Paulo ${ }^{1}$
}

\author{
Fabiana Sala \\ Silvio César Nunes Militão
}

\section{Resumo}

O Plano Nacional do Livro e Leitura estabeleceu eixos e ações para a criação de espaços e condições atinentes à execução de políticas públicas voltadas a garantir acesso às formas mais verticais de informação. Este estudo objetiva analisar o processo de elaboração e implementação do Plano congênere de Anhumas / São Paulo e suas decorrências para a formulação de políticas locais de biblioteca escolar. Um estudo de caso foi realizado, contemplando revisão bibliográfica, entrevista semiestruturada, observação e análise de documentos. A experiência do município em empreender seu Plano demonstra que criar e promover políticas de leitura e biblioteca é um caminho promissor - mas não sem obstáculos, como a restrição orçamentária - para que a população possa ter condições reais de participar, debater e construir conhecimento em âmbito local, com foco no direito fundamental à informação.

Palavras-chave: políticas públicas; biblioteca escolar; políticas educacionais

\section{PUBLIC POLICES OF THE READING AND SCHOOL LIBRARY:} materializacion analysis in Anhumas / São Paulo

\begin{abstract}
National Plan for Book and Reading has determined axis and actions to create spaces and conditions relevant to fulfil public policies addressed to ensure access to more vertical forms of information. This study has as aim at analyzing the elaboration and implementation process of a similar Plan in Anhumas / São Paulo and its consequences to formulate local policies for school library. A case study was carried out encompassing bibliographic review, semi structured interview, observation, and document analysis. This municipality experience to undertake its Plan demonstrates that create and promote policies for Reading and library is a promising path - not without obstacles, such as budget constraint - so that the population might have real conditions to participate, debate and build knowledge in local scope focusing on the fundamental right to information.
\end{abstract}

Keywords: public policies; school library; educational policies

\section{POLÍTICAS PÚBLICAS DE LA LECTURA Y BIBLIOTECA ESCOLAR:} análisis de materialización en Anhumas / São Paulo

\section{Resumen}

El Plan Nacional del Libro y Lectura ha establecido ejes y acciones para la creación de espacios y condiciones pertinentes a ejecución de políticas públicas direccionadas para garantir acceso a las más verticales formas de información. Este estudio tiene el objetivo de analizar el proceso de elaboración e implementación de Plan similar en Anhumas / São Paulo y sus consecuencias para la formulación de políticas locales de biblioteca escolar. Un estudio de caso fue realizado incluyendo revisión bibliográfica, entrevista semiestructurada, observación y análisis de documentos. La experiencia del municipio, en emprender su

\footnotetext{
${ }^{1}$ Este artigo é fruto de pesquisa de mestrado concluída em 2018 no Programa de Pós-graduação em Educação da Faculdade de Ciência e Tecnologia - UNESP.
} 
Plan, muestra que crear y promover políticas de lectura y biblioteca es un camino prometedor - pero no sin obstáculos, como la restricción presupuestaria - para que la población pueda tener condiciones reales para participar, debatir y construir conocimiento localmente, con enfoque en el derecho fundamental a la información.

Palabras clave: políticas públicas; biblioteca escolar; políticas educacionales

\section{INTRODUÇÃO}

Instituir políticas para a formação de leitores é extremamente necessário para democratizar $\mathrm{o}$ acesso a fontes de informação, fomentar a leitura e efetivamente formar leitores competentes por meio de um processo dinâmico, permanente e contínuo. Igualmente, inserir a biblioteca no processo de ensino é fundamental para proporcionar à comunidade escolar a possibilidade de ampliação do conhecimento com vistas à formação crítica, social e cultural. Para tanto, é necessário estabelecer políticas públicas de formação de leitores que estejam além de programas de compra e distribuição de livros, mas que proporcionem às bibliotecas profissionais capacitados, criação de espaços apropriados e recursos para ampliação e manutenção dos acervos, assim como "[...] conhecer essas políticas faz-se importante no que tange à obtenção de recursos para variados fins, como a ampliação do acervo, projetos culturais e capacitações da equipe” (RASTELI, 2013, p. 68).

Com a intenção de caminhar nesse sentido, a Lei n. 13.005/2014, que aprova o atual Plano Nacional de Educação (PNE) e norteia os decorrentes planos infranacionais de educação (estaduais e municipais), mantém algumas diretrizes que abordam a questão das bibliotecas nas instituições de ensino básico. No que se refere às metas e às estratégias que abordam a questão da biblioteca escolar, o PNE reconhece a importância das ações da biblioteca escolar e a sua relação com a qualidade da educação básica, considerando-a como importante equipamento de educação e cultura no ambiente escolar, assim, orienta a implementação das ações estabelecidas pelo Plano Nacional do Livro e Leitura (PNLL) de 2006, formulado para nortear programas e projetos desenvolvidos no âmbito dos Ministérios da Cultura $(\mathrm{MinC})^{2}$ e da Educação (MEC) ${ }^{3}$, bem como de governos estaduais e municipais, instituições públicas e privadas e organizações da sociedade civil, com o objetivo central de:

[...] assegurar e democratizar o acesso à leitura, ao livro, à literatura e às bibliotecas a toda a sociedade, com base na compreensão de que a leitura e a escrita são instrumentos indispensáveis para que o ser humano possa desenvolver plenamente suas capacidades, seja individual ou coletivamente (BRASIL, 2014, p. 23).

No PNLL são estabelecidos eixos e ações que devem ser atingidos a curto, médio e longo prazos, orientando estados e municípios a elaborarem seus próprios planos a fim de criar as condições necessárias para a execução de políticas públicas continuadas, garantindo assim, que a sociedade exerça seus direitos, "[...] melhore, em amplo sentido, seu nível educativo e cultural, fortaleça os valores democráticos, seja criativo, conheça outras culturas, valores e modos de pensar

\footnotetext{
2 Criado através do Decreto n. 91.144, de 15 de março de 1985, a partir do desmembramento do Ministério da Educação e Cultura existente desde 1953, o MinC perdeu seu status de Ministério no dia 2 de janeiro de 2019 com a publicação do Decreto n. 9.674, quando foi transformado em Secretaria Especial da Cultura, inicialmente vinculada ao Ministério da Cidadania e posterior e atualmente - desde 7 de novembro de 2019 - integrada ao Ministério do Turismo. 3 Através do Decreto n. 19.402, de 14 de novembro de 1930, foi criado no Brasil o Ministério da Educação e Saúde Pública, o qual, no ano de 1937 passou a ser denominado Ministério da Educação e Saúde e, em 1953, Ministério da Educação e Cultura. A partir de 1985, em decorrência da criação de Ministério exclusivo para a Cultura (MinC), tornouse apenas Ministério da Educação, mantendo-se a sigla MEC até o presente momento.
} 
de outras pessoas e tenha acesso às formas mais verticais do conhecimento" (BRASIL, 2014, p. 23).

No ano de 2015, como forma de incentivar e orientar estados e municípios brasileiros a elaborarem os seus planos congêneres, foi lançado o Guia de Elaboração e Implementação dos Planos Estadual e Municipal do Livro e Leitura, o qual ressalta que o PNLL “[...] somente ganhará ressonância e efetividade se estados e municípios abraçarem as mesmas preocupações criando as condições para que a política do livro e leitura se implemente efetivamente em âmbito nacional" (GUIA, 2015, p. 6). Contudo, no caso do estado de São Paulo, tanto o governo estadual quanto a imensa maioria das municipalidades paulistas não dispõem ainda dos respectivos planos subnacionais elaborados.

Em recente levantamento realizado junto às prefeituras que fazem parte da Região Administrativa de Presidente Prudente, composta por 53 municípios e localizada a extremo Oeste do estado de São Paulo, constatou-se que, até o presente momento, apenas o município de Anhumas possui o Plano Municipal elaborado e aprovado. Faz-se necessário, portanto, analisar as razões locais e as motivações para formulação e implementação de políticas de biblioteca escolar ${ }^{4}$ no município de Anhumas - São Paulo, a fim de investigar de que maneira a elaboração e a implantação do Plano Municipal do Livro, Leitura e Literatura (PMLLL ${ }^{5}$ ) beneficia a questão da biblioteca escolar na rede de ensino fundamental do município.

Diante de todo o exposto, esta pesquisa tem como objetivo analisar o processo de formulação e implementação do PMLLL no município de Anhumas e decorrentes contribuições em relação à construção de uma política local de biblioteca escolar. Para tanto, optou-se por uma pesquisa de natureza qualitativa, por meio da realização de um estudo de caso (ANDRÉ, 2005) em que nos dispomos da revisão bibliográfica sobre a temática em estudo, entrevista semiestruturada (com 8 sujeitos que participaram da elaboração/implementação do PMLLL), observação e análise de documentos.

\section{A ATUAÇÃO DO ESTADO BRASILEIRO NA ÁREA DO LIVRO, LEITURA E BIBLIOTECA}

As políticas públicas emergem das necessidades da sociedade, por meio do Estado, na busca por solucionar um problema público considerado coletivo, seja ele local ou nacional. Essas políticas, entretanto, também podem surgir da própria sociedade, mesmo que esta possua diferentes crenças e valores, desde que adote atitudes compatíveis com os problemas coletivos porque "[...] a política pública é um conceito abstrato que se materializa por meio de instrumentos variados" (SECCHI, 2010, p. 9).

Nesse aspecto e, sob o amparo da Constituição Federal segundo a qual é dever do Estado garantir a todos o pleno exercício dos direitos culturais e o acesso às fontes de cultura nacional, realizou-se uma conexão entre as principais políticas e programas de fomento à leitura e promoção da biblioteca a fim de retratar a atuação do Estado nessa área.

Apesar da origem das bibliotecas escolares no Brasil remontar ao início da Colônia, ligadas aos primeiros colégios fundados pelos jesuítas no país a partir de meados do século XVI

\footnotetext{
${ }^{4}$ Preconizadas e fomentadas por iniciativas e dispositivos legais de abrangência nacional, conforme detalhado mais adiante.

${ }^{5} \mathrm{O}$ município de Anhumas, dotado da sua autonomia municipal optou por utilizar uma denominação mais abrangente para o seu Plano e acrescentou a palavra Literatura. Com isso, o plano de Anhumas foi denominado como "Plano Municipal do Livro, Leitura e Literatura” (PMLLL).
} 
(CAMPELLO, 2018; MORAES, 2006), durante os períodos colonial ${ }^{6}$ e imperial ${ }^{7}$ o interesse e as iniciativas governamentais atinentes à área do livro, leitura e biblioteca foram ínfimas e só passam a adquirir maior impulso e robustez após a década de 1930, como ilustra a Tabela 1.

Tabela 1: Principais Instituições / Iniciativas do Governo Federal na Área do Livro, Leitura e Biblioteca no Brasil

\begin{tabular}{|c|c|c|c|}
\hline $\begin{array}{l}\text { Instituições/ } \\
\text { Iniciativas }\end{array}$ & Período & Vínculo Institucional & Principais Objetivos \\
\hline $\begin{array}{l}\text { Instituto } \\
\text { Nacional } \\
\text { do Livro } \\
\text { (INL) }\end{array}$ & $\begin{array}{c}1937- \\
1990\end{array}$ & $\begin{array}{l}\text { - } 1937-1953 \text { Ministério da } \\
\text { Educação e Saúde; } \\
\text { - } 1953-1981 \text { MEC; } \\
\text { - 1981-1988 Fundação Pró- } \\
\text { Memória - MinC; } \\
\text { - 1988-1990 Fundação Pró- } \\
\text { Leitura - MinC. }\end{array}$ & $\begin{array}{l}\text { - } \\
\text { - } \text { Impditar, publicar e distribuir livros; } \\
\text { - } \quad \text { Formar recursos humanos qualificados } \\
\text { para atuar nas bibliotecas } \\
\text { (bibliotecários); } \\
\text { - } \quad \text { Coordenar o sistema Nacional de } \\
\text { Bibliotecas Públicas. }\end{array}$ \\
\hline $\begin{array}{l}\text { Serviço Nac. de } \\
\text { Bibliotecas }\end{array}$ & $\begin{array}{l}1961- \\
1969\end{array}$ & $\begin{array}{l}\text { - MEC (foi incorporado pelo } \\
\text { INL) }\end{array}$ & $\begin{array}{l}\text { - Coordenar e promover a integração das } \\
\text { bibliotecas púbicas. }\end{array}$ \\
\hline $\begin{array}{l}\text { Fundação Nac. } \\
\text { Pró-Leitura }\end{array}$ & $\begin{array}{l}1988- \\
1990\end{array}$ & - MinC & $\begin{array}{l}\text { - Coordenar as atividades do INL e da } \\
\text { Biblioteca Nacional }\end{array}$ \\
\hline $\begin{array}{l}\text { Fundação } \\
\text { Biblioteca } \\
\text { Nacional }\end{array}$ & $\begin{array}{l}1990- \\
\text { atual }\end{array}$ & $\begin{array}{l}\text { - MEC; } \\
\text { - Fundação Pró-Leitura - } \\
\text { MinC; } \\
\text { - MinC. }\end{array}$ & $\begin{array}{l}\text { - Coordenar o depósito legal do } \\
\text { patrimônio bibliográfico e documental } \\
\text { do país; } \\
\text { - Promover o acesso à memória cultural; } \\
\text { - Coordenar o PROLER; } \\
\text { - Coordenar o Sistema Nacional de } \\
\text { Bibliotecas Públicas. }\end{array}$ \\
\hline Pró-Leitura & 1992 & - MEC & - Fomentar a leitura em âmbito nacional \\
\hline $\begin{array}{l}\text { Programa } \\
\text { Nacional de } \\
\text { Incentivo à } \\
\text { Leitura- } \\
\text { PROLER }\end{array}$ & 1992 & $\begin{array}{l}\text { - MinC; } \\
\text { - Fundação Biblioteca } \\
\text { Nacional. }\end{array}$ & $\begin{array}{l}\text { Promover o interesse nacional pela } \\
\text { leitura e pela escrita; } \\
\text { - Promover políticas públicas que } \\
\text { garantam o acesso ao livro e à leitura, } \\
\text { contribuindo para a formulação de uma } \\
\text { política nacional de leitura; } \\
\text { - Articular ações de incentivo à leitura } \\
\text { entre diversos setores da sociedade; } \\
\text { - Viabilizar pesquisas sobre livro e escrita. }\end{array}$ \\
\hline $\begin{array}{l}\text { Projeto Uma } \\
\text { Biblioteca em } \\
\text { cada Município }\end{array}$ & $\begin{array}{l}1995- \\
2002\end{array}$ & - MinC & $\begin{array}{l}\text { - Ampliar a rede de bibliotecas públicas } \\
\text { municipais, por meio da distribuição de } \\
\text { recursos para a aquisição de livros, } \\
\text { equipamentos e mobiliários. }\end{array}$ \\
\hline $\begin{array}{l}\text { Programa Nac. } \\
\text { Biblioteca na } \\
\text { Escola }\end{array}$ & 1997 & - MEC & $\begin{array}{l}\text { - Promover a distribuição de livros de } \\
\text { literatura para escolas públicas do país. }\end{array}$ \\
\hline
\end{tabular}

${ }^{6}$ Durante o período colonial destaca-se a criação da Biblioteca Nacional, fundada oficialmente em 29 de outubro de 1810 sob a denominação de Real Biblioteca.

${ }^{7}$ No Império, o desejo do Estado de criar bibliotecas escolares foi expresso pelo Decreto n. 7.247, de 19 de abril de 1879 que, ao reformar o ensino primário e secundário no Munícipio da Corte, determinou também em seu art. $7^{\circ}$ que deveriam ser criadas nos diferentes distritos do referido município pequenas bibliotecas escolares (CAMPELLO, 2018). 


\begin{tabular}{|c|c|c|c|}
\hline $\begin{array}{l}\text { Política Nacional } \\
\text { do Livro }\end{array}$ & 2003 & - Fundo Nacional de Cultura & $\begin{array}{l}\text { - } \quad \text { Estabelece a Política Nacional do Livro; } \\
\text { - Assegurar ao cidadão o pleno exercício } \\
\text { do direito de acesso e uso do livro. }\end{array}$ \\
\hline $\begin{array}{l}\text { Programa Arca } \\
\text { das Letras }\end{array}$ & 2003 & $\begin{array}{l}\text { - Ministério do } \\
\text { Desenvolvimento Agrário }\end{array}$ & $\begin{array}{l}\text { - Implantar bibliotecas rurais e formar } \\
\text { agentes de leitura. }\end{array}$ \\
\hline $\begin{array}{l}\text { Programa Fome } \\
\text { de Livro }\end{array}$ & 2004 & $\begin{array}{l}\text { - Fundação Biblioteca } \\
\text { Nacional }\end{array}$ & $\begin{array}{l}\text { - Instalar mais de } 1000 \text { bibliotecas até } \\
\text { - Ze06; } \\
\text { - Zerar o número de cidades brasileiras } \\
\text { sem biblioteca pública. }\end{array}$ \\
\hline Vivaleitura & 2004 & - $\mathrm{MEC} / \mathrm{MinC}$ & $\begin{array}{l}\text { - Propor políticas para promoção do livro } \\
\text { e da leitura buscando a reversão dos } \\
\text { baixos índices de leitura da população. }\end{array}$ \\
\hline $\begin{array}{l}\text { Plano Nacional } \\
\text { do Livro e } \\
\text { Leitura }\end{array}$ & 2006 & - MEC/MinC & $\begin{array}{l}\text { Assegurar e democratizar o acesso à } \\
\text { leitura e ao livro a toda a sociedade; } \\
\text { - Criar condições e apontar diretrizes para } \\
\text { a execução de políticas, programas, } \\
\text { projetos, e ações por parte do estado e } \\
\text { da sociedade civil; } \\
\text { - Formar leitores, buscando o aumento } \\
\text { do índice nacional de leitura; } \\
\text { - Implantar bibliotecas em todos os } \\
\text { municípios do país. }\end{array}$ \\
\hline Lei n. 12.244 & 2010 & $\begin{array}{l}\text { - MEC/Sistemas de ensino } \\
\text { do País }\end{array}$ & $\begin{array}{l}\text { - Dispõe sobre a universalização das } \\
\text { bibliotecas nas instituições de ensino do } \\
\text { país. }\end{array}$ \\
\hline Lei n. 13.696 & 2018 & - $\mathrm{MEC} / \mathrm{MinC}$ & $\begin{array}{l}\text { - Institui a Política Nacional de Leitura e } \\
\text { Escrita. }\end{array}$ \\
\hline
\end{tabular}

Fonte: SALA, 2018.

Como demonstra a Tabela 1, o período ditatorial que se convencionou denominar de Estado Novo marca o início da institucionalização do primeiro órgão federal destinado à promoção do livro e da biblioteca no Brasil, com a criação do Instituto Nacional do Livro (INL) em 1937, que além de fomentar a edição e comercialização de livros no país foi também crucial para o desenvolvimento da biblioteca pública no território nacional e fundamental "[...] no desenvolvimento da biblioteconomia para a formação de recursos humanos especializados" (ROSA; ODONNE, 2006, p. 186). No final dos anos 1960, o INL encampou o Sistema Nacional de Bibliotecas e, posteriormente, passou a compor as sucessivas instituições voltadas à área do livro, leitura e biblioteca criadas pelo governo federal ao longo da década de 1980: Fundação PróMemória (1981-1988); Fundação Pró-Leitura (1988-1990); e Fundação Biblioteca Nacional, a qual o INL permanece como órgão subordinado desde 1990.

Dos anos 1990 em diante, surgiu uma série de iniciativas federais concernentes à área do livro, leitura e biblioteca escolar, expressas majoritariamente na forma de programas e projetos governamentais, denotando o forte caráter assistemático e intermitente reinante nessa área. Somente no decorrer do século XXI, a partir dos governos populares do PT (2003-2016), inicia-se no país a construção de uma política de Estado - sistêmica, planejada e contínua - direcionada ao livro, leitura e biblioteca escolar, mediante aprovação de legislação específica e edição de Plano correspondente.

Pela Lei n. 10.753, de 30 de outubro de 2003, foi instituída no país a Política Nacional do Livro, demarcando os esforços federais para que as políticas públicas de promoção e acesso ao 
livro e à leitura se projetassem para além do horizonte de duração de um determinado mandato governamental. Essa lei, que veio tratar de importantes questões "[...] relacionadas ao livro, desde a política nacional para a difusão e a leitura, até a editoração, distribuição e comercialização" (ROSA; ODONNE, 2006, p. 188), ensejou a formulação do primeiro Plano Nacional do Livro e Leitura (PNLL) no Brasil.

O PNLL, instituído por meio da Portaria Interministerial MEC/MinC n. 1.442, de 10 de agosto de 2006 e posteriormente regulamentado através do Decreto n. 7.559, de 01 de setembro de 2011, foi elaborado para nortear e conferir organicidade aos distintos programas, projetos e ações atinentes ao livro, leitura e biblioteca, de modo a pautar a área mediante um sistêmico e abrangente planejamento de Estado, articulado e perene. O PNLL, indiscutivelmente, apresentase como uma iniciativa consistente e promissora para a área, por contemplar diferentes eixos de atuação e fornecer caminhos que orientam estados e municípios a elaborar e a executar seus planos congêneres de acordo com a realidade e a necessidade local, pois, acredita-se que, as transformações referentes à promoção da biblioteca escolar podem ser materializadas se houver incentivo e vontade política para atuar em ações que favoreçam a sua instituição e cumpram seu papel educacional e cultural, para atender as necessidades da sua comunidade.

Mais recentemente, a Lei n. $13.696^{8}$, sancionada em 12 de julho de 2018, veio instituir a Política Nacional de Leitura e Escrita (PNLE) como estratégia permanente de promoção do livro, da leitura, da escrita, da literatura e das bibliotecas de acesso público no Brasil, a ser implementada pela União, por intermédio do MinC e do MEC, em cooperação com os estados, o Distrito Federal e os municípios e com a participação da sociedade civil e de instituições privadas. Para tanto, a PNLE determina a formulação, a cada dez anos, de um PNLL, que estabelecerá metas e ações para a consecução da referida política, o qual deve ser "[...] elaborado nos 6 (seis) primeiros meses de mandato do chefe do Poder Executivo" (BRASIL, 2018, art. $\left.4^{\circ}, \$ 1^{\circ}\right)$. Entretanto, o novo PNLL demandado pela PNLE ainda não foi materializado?.

Cumpre ressaltar, também, que o Brasil ainda não possui uma Política Nacional de Bibliotecas instituída ${ }^{10}$ e que a legislação mais recente e emblemática acerca da questão da biblioteca no país é a Lei n. 12.244, de 24 de maio de 2010, a qual veio determinar que todas as instituições de ensino do país possuam uma biblioteca no prazo de dez anos. Mas, diante da inefetividade da referida Lei para o alcance da universalização das bibliotecas escolares no Brasil dentro do prazo originalmente estabelecido (até 2020), encontra-se em tramitação no Congresso Nacional um Projeto ${ }^{11}$ que adia em quatro anos o período para que tal universalização seja efetivada, a qual deve ocorrer no máximo até o fim da vigência do corrente PNE (ou seja, até 25 de junho de 2024).

Não obstante os avanços alcançados no país, a efetivação de políticas de Estado e correspondente materialização de planos relativos à área do livro, leitura e biblioteca vem, nos

\footnotetext{
${ }^{8}$ Originada da aprovação do Projeto de Lei n. 212, apresentado ao Congresso em maio de 2016 pela Senadora Fátima Bezerra (PT/Rio Grande do Norte).

${ }_{9}^{9}$ Estabelecido pela Lei n. 13.696/2018 sancionada ainda no Governo Temer, o novo PNLL deveria ter sido elaborado pelo Governo Bolsonaro até o dia 30 de junho de 2019, com vigência para o decênio seguinte. Mas o atual Governo, revelando seu desapreço pela Cultura, além de extinguir o MinC e promover recorrentes trocas no comando da atual Secretaria Especial da Cultura (quatro mudanças realizadas em apenas um ano e meio), vem desde o início da gestão negligenciando as políticas instituídas para a área e, notadamente, a formulação do novo PNLL, que se encontra paralisada.

10 O Projeto de Lei n. 28/2015, de autoria do Senador Cristovam Buarque (PDT/DF), propõe a instituição de uma Política Nacional de Bibliotecas para o país, o qual se encontra na Comissão de Assuntos Econômicos do Senado Federal aguardando parecer final.

11 Trata-se do Projeto de Lei n. 9.484/2018, de autoria da Deputada Federal Laura Carneiro (PMDB/RJ), aprovado pela Câmara dos Deputados em 10/10/2019 e que aguarda apreciação do Senado Federal.
} 
últimos tempos, trilhando caminho pedregoso, notadamente a partir do impeachment da presidência de Dilma Rousseff, o qual simboliza a ruptura com o período dos governos populares do PT e marca o despontar de uma nova época de "neoliberalismo extremado" no Brasil.

O neoliberalismo, que surgiu logo após o final da Segunda Guerra Mundial como uma reação teórica e política ao chamado Estado de Bem-estar Social ${ }^{12}$, “[...] luta contra o estatismo, ou seja, contra o Estado máximo, contra o planejamento econômico, contra a regulamentação da economia e contra o chamado protecionismo [...]", advoga a saída do Estado "[...] do setor de produção (por sua privatização) [...]" e postula a "[...] diminuição de gastos do fundo público em políticas públicas e sociais" (LIBÂNEO, OLIVEIRA, TOSCHI, 2012, p. 100). Entretanto, somente com a crise de acumulação do capital dos anos 1970 é que efetivamente aparece "[...] a necessidade de uma reformatação do Estado [...]" (DEL ROIO, 2020, p. 225) e o modelo keynesiano de Estado passa a ser gradativamente suplantado pelo modelo neoliberal de "Estado mínimo", notadamente após sua adoção pelos governos de Margaret Thatcher (Inglaterra) e Ronald Reagan (Estados Unidos), no início dos anos 1980, alcançando hegemonia em escala mundial a partir da década de 1990.

No caso da América Latina, particularmente, a virada para o neoliberalismo ocorre na segunda metade da década de 1980, especialmente quando políticos alinhados aos pressupostos neoliberais alcançam a presidência de seus respectivos países: “[...] Salinas, no México, em 88, [...] Menem, na Argentina, em 89, [...] Perez, no mesmo ano, na Venezuela, [...] Fujimori, no Peru, em 1990" (ANDERSON, 1996, p. 20). Já no Brasil, a implantação do modelo neoliberal e a redefinição / minimização do Estado (nos campos econômico e social) tem início no Governo de Fernando Collor de Mello (1990-1992) e ganha consistência e intensificação no duplo Governo de Fernando Henrique Cardoso (1995-1998/1999-2002). É por isso que, de meados da década de 1990 em diante, "[...] o país tornou-se o reino das reformas institucionais - a começar pelo Estado e pela educação - bem como da privatização das empresas estatais" (SILVA JÚNIOR; FERRETI, 2004, p. 29).

Ao longo do período em que o PT (2003-2016) esteve à frente da condução do país, a agenda neoliberal foi amainada no Brasil, cuja marca distintiva foi a priorização das políticas sociais (POCHMANN, 2013; SADER, 2013). Nesse sentido, conforme apontam Gentili e Oliveira (2013), “[...] o governo democrático-popular iniciado por Lula inverteu significativamente o processo de desinvestimento social que tinha caracterizado o governo neoliberal do seu antecessor, [quando] as políticas sociais sofreram cortes significativos [...]".

Com o esgotamento do ciclo petista e assunção definitiva de Michel Temer à presidência da República, após consumação do "[...] golpe jurídico-midiático-parlamentar [...]" (SAVIANI, 2018, p. 45) em 31 de agosto de 2016, o Brasil ingressa numa fase de "[...] radicalização do neoliberalismo [...]" (DEL ROIO, 2020, p. 229), cuja medida mais representativa consiste na aprovação da Emenda Constitucional n. 95, de 15 de dezembro de 2016, a qual institui no país um novo - e severo - regime fiscal e "congela" por vinte anos (que se estenderão, portanto, até 2036) os gastos e investimentos públicos nas políticas sociais, de modo a obstaculizar consideravelmente as políticas e planos de Estado concernentes às áreas educacional e cultural. Tal ajuste fiscal tem

$12 \mathrm{O}$ modelo do chamado Estado de Bem-estar Social, fundamentado na teoria keynesiana de Estado forte e interventor, foi adotado por parte significativa dos países do centro do capitalismo após a Segunda Guerra Mundial e pode ser caracterizado como o modelo de Estado que favorece tanto o processo de acumulação capitalista quanto a garantia de direitos sociais fundamentais aos cidadãos (como saúde, educação, habitação, previdência) e que, portanto, desempenha múltiplas funções: planeja, administra e regula a economia de mercado; participa direta e ativamente da esfera econômica, com a produção de bens e serviços; e promove as políticas públicas sociais (BIANCHETTI, 1999; LIBÂNEO, OLIVEIRA, TOSCHI, 2012). 
continuidade no governo ultraliberal-conservador de Jair Bolsonaro (2019-2022), o qual acirra ainda mais a agenda neoliberal retomada pelo Governo Temer (2016-2018), sendo a aprovação da Reforma da Previdência o exemplo mais recente e emblemático de retrocesso e supressão dos direitos sociais fundamentais e da primazia atualmente conferida à política econômica do chamado "Estado mínimo".

\section{Das políticas nacionais às práticas locais}

Com a promulgação da Constituição Federal de 1988, que elevou os municípios brasileiros à condição de entes federados autônomos, a edição da Lei de Diretrizes e Bases da Educação Nacional (LDB) de 1996, o processo de descentralização do ensino deflagrado pelo governo federal e o incentivo estadual à municipalização do ensino fundamental, abre-se a possibilidade de organização dos Sistemas Municipais de Ensino.

Neste cenário de descentralização político-educacional, os municípios passam a responsabilizar-se, crescentemente, pela oferta e gestão de parte considerável da educação escolar básica, sobretudo da educação infantil e dos anos iniciais do ensino fundamental (AIEF). Dotados de maior autonomia no campo educacional, os municípios são impelidos pelas principais legislações nacionais a elaborarem políticas educacionais próprias que atendam às suas especificidades locais.

Ao analisar a Lei Orgânica de Anhumas que tem por finalidade estabelecer as diretrizes locais que servem como base para o desenvolvimento no campo da educação, da cultura, do esporte e do lazer do município, constata-se que ela não aborda a questão da biblioteca escolar, silenciandose sobre o seu papel no processo de formação. O mesmo ocorre com o Plano Municipal de Educação (PME) que, apesar de apresentar-se como elaborado de acordo com as recomendações nacionais estipuladas no PNE, também não menciona em nenhuma meta ou ação o termo.

Embora a biblioteca escolar não esteja contemplada nas principais legislações do município, Anhumas destaca-se estadual e nacionalmente por ter elaborado e implementado o seu Plano Municipal do Livro, Leitura e Literatura, em conformidade com o disposto no PNLL. Mesmo com ampla divulgação de "Guia para a elaboração e implantação dos Planos estadual e municipal do livro e leitura", atualmente ainda são raros os estados e municípios brasileiros que o fizeram, conforme apresenta a Tabela 2. 
Tabela 2: Planos do Livro e Leitura no Brasil - situação estadual e municipal

\begin{tabular}{|l|l|l|l|}
\hline PLANO & ESTADOS & SITUAÇÃO & ANO \\
\hline PDLL & Distrito Federal & Aprovado & \\
\hline PELL & Rio Grande do Sul & Aprovado & 2013 \\
\hline PELL & Paraná & Aprovado & 2013 \\
\hline PELL & Rio Grande do Norte & Aprovado & \\
\hline PELL & Bahia & Aprovado & \\
\hline PELL & Tocantins & Aprovado & \\
\hline PELL & Mato Grosso do Sul & Aprovado & \\
\hline PELL & Santa Catarina & Em construção & 2015 \\
\hline PELL & Ceará & Em construção & \\
\hline PELL & Sergipe & Em construção & \\
\hline PELL & Rio de Janeiro & Em construção & 2015 \\
\hline PELL & Minas Gerais & Em construção & 2014 \\
\hline PELL & Mato Grosso & Em construção & 2017 \\
\hline PELL & Pernambuco & Em construção & 2017 \\
\hline PLANO & MUNICÍPIOS & SITUAÇÃO & ANO \\
\hline PMLL & Salvador - BA & Em construção & \\
\hline PMLL & Fortaleza - CE & Em construção & \\
\hline PMLL & Belém - PA & Em construção & \\
\hline PMLL & Canoas - RS & Aprovado & 2010 \\
\hline PMLL & Porto Alegre - RS & Aprovado & 2011 \\
\hline PMLL & Joinville - SC & Aprovado & 2013 \\
\hline PMLL & Nova Iguaçu - RJ & Aprovado & 2014 \\
\hline PMLL & São José do Rio Preto - SP & Em construção & 2014 \\
\hline PMLLLB & São Paulo - SP & Aprovado & 2015 \\
\hline PMLL & Curitiba - PR & Em construção & 2015 \\
\hline PMLL & Campo Grande - MS & Aprovado & 2016 \\
\hline PMLL & Peabiru - PR & Aprovado & 2016 \\
\hline PMLL & São João Del Rey - MG & Em construção & 2016 \\
\hline PMLLL & Anhumas - SP & Aprovado & $\mathbf{2 0 1 6}$ \\
\hline PMLLB & Ribeirão Preto - SP & Aprovado & 2017 \\
\hline PMLL & Presidente Prudente - SP & Em construção & 2017 \\
\hline & & \\
\hline
\end{tabular}

Fonte: Adaptado de Pinheiro (2016), com atualização pelos autores em março de 2018.

A construção de tal Plano pelo município de Anhumas consiste na primeira iniciativa municipal própria a contemplar a área do livro, leitura, literatura e biblioteca de forma consciente e comprometida, o que representa um grande avanço na gestão e uma forte influência da representação cultural do município, uma vez que, passa a empenhar esforços para criar ações e conscientizar a população da importância da biblioteca na formação cidadã e no desenvolvimento local.

Apesar do breve período de implementação, o PMLLL de Anhumas já tem alcançado diversas ações: distribuição de geladeiras com obras literárias para consulta pública em setores como a saúde e o esporte; realização do Dia Municipal da Leitura de Anhumas; contação de histórias e sessões de cinema; encontro com autores; sarais e acampamentos literários e; promoção de encontros intergeracionais entre crianças e idosos, que consistem em aproximar a troca de experiências e valorização história local. Assim, experiência do município de Anhumas em empreender o seu PMLLL demonstra que criar e promover políticas públicas de leitura e biblioteca é um caminho promissor para que a população possa ter, de fato, informação e leitura capazes de 
criar debates e de construir conhecimento, com foco no direito fundamental à informação no Brasil.

\section{PROCESSO DE ELABORAÇÃO E IMPLEMENTAÇÃO DO PMLLL}

Desde a chamada Primeira República, a criação e manutenção das bibliotecas escolares por muitas vezes foi fruto mais da luta e esforço de idealistas convencidos da necessidade da sua presença definitiva nas escolas brasileiras do que de mérito governamental (CAMPELLO, 2018). No caso de Anhumas, igualmente, a estreita relação do então Assessor de Turismo e Cultura e também servidor responsável pela Biblioteca Municipal há onze anos com a matéria, assim como o seu grande interesse pela temática, foi crucial para influenciar na decisão de criação de um PMLLL em um município de pequeno porte populacional, relativamente novo e economicamente dedicado ao setor primário ${ }^{13}$.

Após tomar conhecimento do PNLL e da recomendação nacional de que cada município deveria elaborar seu correspondente plano, o Assessor procurou a Secretária de Educação local e solicitou parceria para criar um grupo de trabalho com a finalidade de elaborar o PMLLL do município. Foi constituída então a comissão de feitura do PMLLL de Anhumas, composta por nove integrantes que representavam diferentes segmentos, a saber: 1- Departamento de Turismo e Cultura; 2- Secretaria Municipal de Educação; 3- Pré-escola; 4- Escolas Municipais; 5- Escola Estadual; 6- Creche Municipal; 7- CRAS; 8- Assistência Social; e 9- Paço Municipal.

Essa integração de diferentes segmentos para a construção do PMLLL consiste em um aspecto altamente positivo, pois, de acordo com as recomendações do "Guia PELL e PMLL", o município deve procurar

[...] integrar o Plano aos demais setores da administração (Cultura, Educação, Social, Meio Ambiente etc.) e buscar sempre incluir em documentos oficiais a questão da leitura entre as diretrizes para outras políticas públicas, que versam sobre questões como direitos humanos, saúde, crianças e adolescentes, políticas afirmativas, trabalho infantil etc. (GUIA, 2015, p. 18).

O "Guia PELL e PMLL" recomenda a realização de um diagnóstico “[...] da situação existente na área do livro e leitura na cidade de forma a orientar a elaboração do Plano e a definição de políticas, metas e ações" (GUIA, 2015, p. 11). Assim, constituída a comissão, a primeira ação do grupo foi realizar uma pesquisa de opinião pública, na qual foram entrevistadas 156 pessoas de diversos segmentos. Essa pesquisa teve como finalidade traçar o perfil dos leitores do município e identificar suas necessidades. O resultado constatou que: $71 \%$ dos entrevistados afirmam gostar de ler, $36 \%$ declaram que frequentam a biblioteca e apenas $24 \%$ dizem retirar livros para empréstimo domiciliar.

Apesar das pessoas gostarem de ler o acesso ao livro por meio da biblioteca ainda é pouco e com isso o Plano Municipal do Livro, Leitura e Literatura, justifica-se da necessidade de democratização de acesso ao livro e fomento à leitura como meio de melhoria nos indicadores de desenvolvimento humano e socioeconômicos do município a fim de que as pessoas possam frequentar mais as bibliotecas públicas e com isso elevar o índice de leitores (ANHUMAS, 2016, p. 6).

\footnotetext{
13 O município de Anhumas foi emancipado politicamente em 1953, possui população de 3.898 habitantes e economia sustentada na agropecuária (SEADE, 2018).
} 
De posse do diagnóstico da pesquisa, a comissão passou a reunir-se regularmente para estudar as disposições do PNLL, do Guia de elaboração do PMLL e, também, o conteúdo de planos correlatos já aprovados por outros municípios, de modo a subsidiar a definição das ações próprias contempladas no PMLLL elaborado por Anhumas.

Quando o município não tem plano fica à mercê de ações episódicas que, mesmo planejadas caso a caso, representam improvisações. Sem plano municipal não há visão de Estado nas ações, não há caminho a percorrer, mas apenas passos ao sabor das circunstâncias de cada Governo (BORDIGNON, 2009, p. 92).

Se a aprovação de um plano municipal já é uma tarefa laboriosa, “[...] mais difícil ainda é garantir sua implantação de forma efetiva" (PINTO, 2017, p. 17), para a qual se faz necessária a devida dotação orçamentária. A ausência de previsão orçamentária no plano compromete significativamente a sua materialização, pois, assegurar os recursos financeiros "[...] se constitui como a condição prévia e necessária de viabilidade de todas as demais metas” (SAVIANI, 2008, p. 318).

Neste aspecto, a experiência de Anhumas revela-se consideravelmente fragilizada, pois o grupo encarregado da construção do plano destacou que o maior obstáculo durante o processo de elaboração do PMLLL foi propor metas e ações que não envolvessem recursos financeiros para a execução, uma vez que a operacionalização do Plano no município não prevê orçamento. Portanto, o PMLLL de Anhumas, não obstante o grande empenho do grupo envolvido com a sua consecução, não deixa de correr o risco de passar, na prática, "[...] de uma carta de intenções" (SAVIANI, 2008, p. 278), dada a inexistência de recursos governamentais para assegurar a implementação de todo o plano.

Como órgão executor do PMLLL, a Assessoria de Turismo e Cultura é responsável por realizar periodicamente a Conferência Municipal do PMLLL para debater estratégias e estabelecer cooperação entre os agentes públicos e a sociedade civil para o cumprimento das metas e ações propostas. Entre os principais avanços já observados sobre a implantação do Plano, os atores destacam a parceria que se fortaleceu entre os diversos setores do município. As Gelatotecas são um exemplo das ações propostas no Plano que estão sendo desenvolvidas em parceria com os Departamentos de Esporte e Saúde do município, com o objetivo de incentivar a leitura e de espalhar livros, ideias e informações para o fortalecimento da população, transformando os locais de espera em "Cantinhos da leitura". Assim como o projeto da Gelatoteca, diversas ações previstas no Plano já estão sendo realizadas no município.

\section{Expectativas sobre o PMLLL}

Ao iniciar o processo de elaboração do Plano, o coordenador relata que suas expectativas foram motivadas pela possibilidade de as ações do PMLLL contribuírem para a promoção do crescimento social e cultural da população e para formação crítica e cidadã da comunidade. Ele relata, ainda, a importância de promover ações com determinação e entusiasmo e de acreditar no poder transformador dessas ações para alcançar o maior número de pessoas. Os demais responsáveis pela formulação do Plano, por sua vez, demonstram confiança no trabalho que está sendo desenvolvido e se mostram muito motivados a executar as ações que são planejadas pelo grupo, bem como procuram estar atentos e cobrar para que elas aconteçam e o PMLLL possa ser efetivado no município.

De acordo com o "Guia PELL e PMLL", a avaliação é uma das etapas mais importantes das políticas públicas, pois é por meio dela que são possíveis a realização dos ajustes necessários. 
Portanto, é preciso que essa fase seja prevista desde a elaboração do Plano. "Ela pode ter uma periodicidade definida previamente: ser, por exemplo, semestral, anual ou bianual. O importante é avaliar como está sendo implantado o PLL e se as metas estabelecidas inicialmente estão sendo plenamente alcançadas" (GUIA, 2015, p. 30). Nesse sentido, o PMLLL de Anhumas prevê a formação e a manutenção de um conselho gestor com a participação de membros do funcionalismo público e da sociedade civil, com realização de conferências bienais, tendo em vista monitorar e avaliar a execução do referido Plano.

A articulação de parcerias é orientada no "Guia PELL e PMLL" como um requisito fundamental para cumprir as ações previstas no Plano. De acordo com o Guia, é essencial estabelecer compromissos com diferentes pessoas e entidades, a fim de realizar ações conjuntas e de gerir o Plano de modo participativo. "A articulação é fundamental para assegurar uma boa execução do Plano, evitando dispersão de esforços e, ainda, otimizando os recursos, ao permitir maior abrangência do Plano e um número maior de beneficiados" (GUIA, 2015, p. 22).

Destarte, o envolvimento de diferentes setores na construção e na execução das ações do PMLLL é considerado por todos os envolvidos com tal plano como uma grande conquista e um resultado positivo do empenho deles em disseminar a leitura e envolver a comunidade. Assim, todos reconhecem a importância do PMLLL para o desenvolvimento da cidade e mostram-se satisfeitos com as ações que estão sendo desenvolvidas e com os avanços já obtidos.

O Salão do Livro de Anhumas já vinha sendo realizado pelo Departamento de Turismo e Cultura desde 2015, anteriormente à instituição do PMLLL em dezembro de 2016. Entretanto, a partir de 2017, ele passou a ser promovido como uma das ações do Plano e, desde então, conta com o apoio de diversos setores da comunidade que antes não conseguia envolver. Sem dúvida, a proposta de iniciar as ações do PMLLL a partir do fortalecimento de ações já praticadas no município demonstra a valorização e o respeito do grupo às iniciativas anteriormente existentes e passíveis de fortalecimento a partir da vigência do Plano recém-criado.

O grupo local dedicado ao PMLLL mostra-se, incansavelmente, disposto a trabalhar no desenvolvimento de ações que envolvam maior público e alcancem diferentes faixas etárias, desde os bebês até a terceira idade, a fim de criar uma cultura e mudar o hábito da população local. No entanto, o grupo reconhece que muito ainda precisa ser melhorado e implementado no município, conforme as atividades forem se desenvolvendo e a comunidade for se envolvendo mais com o Plano municipal atualmente vigente.

\section{Contribuições do PMLLL para as bibliotecas escolares do município}

Apesar dos intentos registrados desde o período imperial, a “[...] ausência de previsão de recursos [sempre inviabilizou] a existência de bibliotecas em todas as escolas" (CAMPELLO, 2018, p. 483) do país, situação que perdura na atualidade. Além da grande distância em relação à universalização da biblioteca escolar no Brasil, os dados de 2018 do Censo Escolar do MEC, compilados por Cruz e Monteiro (2019), permitem verificar como também é grande a discrepância quanto à presença de biblioteca e/ou sala de leitura por nível de ensino público no cenário nacional, cuja porcentagem é de: $15,4 \%$ na creche; $15,7 \%$ na pré-escola; $48,1 \%$ no ensino fundamental; e $85,7 \%$ no ensino médio.

Em Anhumas a rede municipal de ensino é composta por três instituições públicas de ensino: creche (para crianças de 0 a 3 anos), pré-escola (destinada aos alunos de 4 a 5 anos) e EMEF (para estudantes do $1^{\circ}$ ao $5^{\circ}$ ano do ensino fundamental). Porém, apenas a escola voltada ao ensino fundamental possui uma biblioteca escolar, ao passo que as outras duas (pertencentes à educação 
infantil) dispõem tão somente de espaços específicos para atividades relacionadas à leitura, os quais são denominados como "Cantinhos e/ou Salas de Leitura".

A experiência de Anhumas, além de reafirmar a histórica condição estrutural da educação infantil como espécie de "primo pobre" no âmbito dos sistemas educativos do país e reforçar uma equivocada "[...] noção de que biblioteca escolar pode ser acomodada em qualquer espaço, por mais acanhado e exíguo que seja" (CAMPELLO, 2018, p. 484), denota que o comprometimento e esforço hercúleo do grupo idealizar e executor do PMLLL, ainda que louvável, não bastam para garantir que a biblioteca exista de fato na totalidade das suas instituições de ensino, de modo a evidenciar as fragilidades municipais, sobretudo de ordem financeira ${ }^{14}$, para implantar políticas públicas de universalização da biblioteca escolar e de formação de leitores e dar continuidade a elas.

A EMEF, além de ter um espaço próprio, construído especificamente para ser a biblioteca escolar, também conta com pessoa designada (uma professora) exclusivamente para atuar no ambiente, gerenciar o espaço e elaborar/desenvolver atividades com alunos e professores, tornando-se um diferencial em relação às outras escolas. A biblioteca da EMEF oferece grande variedade de matérias para trabalhar diferentes estratégias de leitura e aprendizagem e os alunos já se apropriaram do espaço. Com a professora designada à frente da biblioteca, a EMEF começou a contar com projetos direcionados para o incentivo à leitura e à pesquisa e as ações por ela desenvolvidas têm alcançado bons resultados, pois os professores têm procurado apoio para desenvolver atividades em sala de aula, os alunos passaram a utilizar mais o ambiente e têm solicitado cada vez mais a aquisição de novos títulos e materiais.

Visando alcançar as metas propostas no PMLLL, o grupo responsável optou por integrar e abrir os acervos para atender a todos os alunos, independentemente de possuir o vínculo da matrícula. No entanto, os sujeitos ainda não conseguem vislumbrar que esse crucial instrumento pode ser utilizado como importante ferramenta de luta para alcançar a tão almejada universalização da biblioteca escolar no âmbito local, mediante construção de necessárias e novas bibliotecas e da correspondente contratação de bibliotecários, de modo a fortalecer a própria rede escolar municipal, conforme preconiza a Lei n. 12.244/2010.

Os sujeitos da pesquisa concordam que a biblioteca é um espaço imprescindível para a formação dos alunos. Portanto, afirmam que todas as escolas do município, independentemente de possuir efetivamente uma biblioteca escolar (existente somente na EMEF, ainda que sem dispor de profissional devidamente especializado), realizam trabalhos pedagógicos no âmbito da leitura mediante projetos, os quais fazem parte da rotina escolar e estão previstos no Projeto Pedagógico (PP) das instituições de ensino. $\mathrm{Na}$ creche municipal, por exemplo, a coordenadora ressalta a importância do Cantinho da Leitura e dos projetos desenvolvidos pela escola, como sendo a única forma de contato com o livro e com a leitura para muitos alunos.

A preocupação em proporcionar experiências com a leitura desde a primeira infância demonstra a compreensão por parte dos sujeitos de que tanto os bebês quanto as crianças pequenas são capazes de estabelecer relações e, consequentemente, de aprender, além de contribuir para o seu desenvolvimento físico, social, psíquico e afetivo (MUKHINA, 1996). Dessa forma, é fundamental proporcionar acesso aos livros e práticas de leitura de maneira individual e coletiva.

As atividades desenvolvidas pela biblioteca escolar (ou cantinho/sala de leitura) são de grande importância para a construção do desenvolvimento crítico e das habilidades do aluno, por isso devem estar necessariamente contempladas no PP da escola, uma vez que, "[...] um projeto educativo pode ser tomado como promessa frente a determinadas rupturas. As promessas tornam

\footnotetext{
${ }^{14}$ Em Anhumas não há dotação orçamentária específica destinada à biblioteca escolar, que possa custear reformas, aquisição de acervos, mobiliários e demais materiais.
} 
visíveis os campos de ação possíveis, comprometendo seus atores e autores" (GADOTTI, 2000, p. 37).

Cabe registrar que a presença da biblioteca nos PPs das escolas está contemplada apenas com relação ao desenvolvimento das atividades desenvolvidas no âmbito da leitura. Porém, a biblioteca escolar é um importante instrumento na construção do conhecimento social, político e cultural da comunidade e o PP é o documento que norteia as ações da instituição para alcançar seus objetivos. Assim, a biblioteca não pode ser representada unicamente por meio de um projeto de leitura específico, mas deve ser configurada de forma mais abrangente, explicitando sua função e as ações que podem ser desenvolvidas por esse ambiente visando à formação integral da comunidade escolar.

A biblioteca escolar possui funções que vão muito além do acesso ao livro e à leitura. Sua presença ou ausência no PP da escola reflete a importância e a compreensão por parte dos sujeitos sobre o seu papel e retrata a contribuição no processo de aprendizagem. Além do fato de que, por não ter um ambiente adequado, e bibliotecários, a qualidade das atividades que são realizadas acaba sendo prejudicada.

Um dos princípios do PMLLL de Anhumas é o “[...] fortalecimento das bibliotecas e demais espaços destinados a difusão do livro, da leitura e da literatura" (ANHUMAS, 2016, p. 7). Visando alcançar esse objetivo, o grupo local responsável tem trabalhado a fim de promover interações e parcerias. Essa articulação é fundamental para "[...] garantir a continuidade do Plano e sua efetiva legitimação perante o conjunto da sociedade" (GUIA, 2015, p. 13). Porém, é necessário fortalecer essa cooperação para o desenvolvimento de ações que vão além das atividades de leitura, para que alcancem força e consistência para conquistar novas metas, tais como a construção de espaços adequados para abrigar as bibliotecas nas escolas que ainda não os possuem e a contratação de profissionais especializados na área para atuar nesses ambientes.

O Eixo 1 do PNLL (Democratização do acesso) recomenda que sejam empenhados esforços para a valorização das bibliotecas enquanto polo difusor de informação e cultura. Para isso, os Planos Municipais devem esforçar-se para propor ações de revitalização e de implantação de novas bibliotecas, articular e fortalecer a criação de redes com vistas a conquistar novos espaços de leitura, a fim de que essas bibliotecas possam ser reconhecidas e utilizadas como verdadeiros centros " [...] de educação continuada e núcleo de lazer e entretenimento, estimulando a criação e a fruição de diversos bens artístico-culturais" (GUIA, 2015, p. 18), e não mais como meros depósitos de livros.

\section{Articulação da gestão do municipal para o alcance das metas}

O Coordenador do PMLLL, responsável por acompanhar e avaliar as ações do Plano, relata que faz o possível para implementar as ações do Plano. Porém, muitas vezes, acaba tendo dificuldades por não ter formação específica. Diante das dificuldades, ele está sempre buscando informações e articulando-se com diferentes setores para o desenvolvimento das atividades. Esse esforço em conquistar e manter parceiros é visto como fundamental para o sucesso e para a continuidade das ações, conforme dispõe o "Guia PELL e PMLL".

É importante estabelecer compromissos com o maior número possível de pessoas e entidades relacionadas ao livro e à leitura no município para realização de ações conjuntas e também para uma gestão participativa do Plano. A articulação é fundamental para assegurar uma boa execução do Plano, evitando dispersão de esforços e, ainda, otimizando os recursos, ao permitir maior abrangência do Plano e um número maior de beneficiados (GUIA, 2015, p. 23). 
$\mathrm{Na}$ avaliação do Coordenador, conquistar essa cooperação é fundamental, inclusive, para "driblar" a escassez de recursos financeiros, pois com maior auxílio humano é possível desenvolver diversas atividades mesmo sem necessariamente dispor de capital. Um bom exemplo é a participação de pessoas ligadas à Biblioteca Pública do município em iniciativas desenvolvidas gratuitamente pela Secretaria de Cultura do Estado, que muito contribui para a formação social e cultural da comunidade local.

O Coordenador também destaca o PMLLL como um grande marco no município, capaz de contribuir significativamente para o processo de transformação de cidadãos leitores e para o alcance de melhores índices de desenvolvimento humano e social. Contudo, tanto ele quanto os demais responsáveis pelo Plano até então desconheciam o completo teor da Lei n. 12.244/2010, fundamental para dar suporte a tal processo.

Como visto, apenas uma (a EMEF) das três escolas municipais de educação básica conta com espaço adequado para a biblioteca escolar e, mesmo assim, sem possuir em seu quadro de servidores o profissional bibliotecário, conforme preceitua a legislação supracitada. Há anos lutando pela disponibilização de, ao menos, uma vaga de bibliotecário especializado em concurso público da Prefeitura, a Secretária Municipal de Educação, ao envolver-se com as ações do PMLLL e tomar conhecimento integral da Lei n. 12.244/2010, poderá ganhar mais força em sua reinvindicação.

\section{CONSIDERAÇÕES FINAIS}

Indubitavelmente, instituir políticas públicas de leitura e biblioteca é fundamental para democratizar o acesso às fontes de informação, fomentar a leitura e garantir a formação de leitores competentes por meio de um processo dinâmico, permanente e contínuo. Contudo, ao passar em revista a história nacional atinente à área, constatou-se que os intentos federais relativos à promoção do livro, da leitura e da biblioteca no Brasil sempre foram pontuais e esparsos, esmaecendo na maioria das vezes em razão da falta de priorização política, ausência de previsão de recursos e da recorrente descontinuidade. Como decorrência, o país adentra o século XXI sem ter conseguido formular e implantar antes uma orgânica e consistente política de Estado para o setor, historicamente marcado pela primazia conferida à distribuição de livros em detrimento da formação do leitor.

O advento da Política Nacional do Livro (instituída em 2003) e a formulação do correspondente PNLL (em 2006) demarcam a virada do país em direção à construção de uma política e de um planejamento de Estado concernente à área do livro, leitura e da biblioteca escolar, como antídoto as episódicas e descontínuas iniciativas governamentais tradicionalmente prevalentes no Brasil. Assim, o PNLL surge para conferir aos variados programas e projetos a necessária organicidade e perenidade, de modo a nortear a articulação de esforços de ministérios, governos estaduais e municípios, organizações gerais e sociedade civil em prol da concretização de abrangente e efetiva política pública nacional do livro, da leitura e da biblioteca escolar.

Sem dúvida nenhuma, o caminhar no sentido de tal concretização - ainda que insuficiente - é significativo e o PNLL, particularmente, apresenta-se como uma iniciativa consistente e promissora para a área, por contemplar diferentes eixos de atuação e orientar estados e municípios na elaboração e execução de seus planos congêneres de acordo com a realidade e a necessidade local. Entretanto, num contexto contemporâneo de retomada e acirramento do neoliberalismo extremado, pautado pela prioridade às políticas de ajuste fiscal e secundarização das políticas sociais, as limitações orçamentárias impostas pela vigente Emenda Constitucional n. 95/2016 
obstaculiza consideravelmente a materialização de planos subnacionais direcionados ao livro, leitura e à biblioteca.

No caso das municipalidades, em especial, o cenário que o país atravessa é mais impactante ainda, pois elas já se constituem na esfera de poder mais díspar e assimétrica da Federação, com enormes carências estruturais, administrativas, humanas e financeiras para implantar políticas públicas em âmbito local. De acordo com os números do Instituto Brasileiro de Administração Municipal (IBAM), os municípios brasileiros, na grande maioria $(74,8 \%$ deles), praticamente não dispõem de recursos próprios para custear iniciativas locais e são altamente dependentes das transferências governamentais da União e do estado.

O município de Anhumas, especificamente, um dos raros do estado de São Paulo a ter aprovado seu PMLLL, apesar do exíguo tempo de implementação, tem conseguido alcançar diversos objetivos e realizado ações que visam a atender as metas estabelecidas. Portanto, a institucionalização do referido Plano constitui grande avanço e a experiência de Anhumas em empreender o PMLLL demonstra que promover localmente programas de leitura e biblioteca é um caminho promissor para que a população possa ter condições reais de participar, debater e construir conhecimento em âmbito local, com foco no direito fundamental à informação.

Entretanto, não obstante o grande empenho do grupo envolvido com a implementação do PMLLL, a consecução de cruciais ações atinentes à biblioteca escolar encontra sérias limitações na escassez de recursos, que inviabiliza a existência de bibliotecas e bibliotecários na totalidade das instituições municipais de ensino, evidenciando as fragilidades locais para materializar políticas de universalização da biblioteca escolar e de formação de leitores.

Considerando que a concretização de políticas públicas exige dotação orçamentária e tendo em vista os ínfimos recursos municipais, recomenda-se aos gestores públicos federais que reconheçam os esforços e, sobretudo, as dificuldades dos municípios pioneiros na instituição de seus PMLLs, como Anhumas, e os apoie financeiramente no momento da implementação das ações voltadas ao livro, leitura e biblioteca escolar, inclusive como mecanismo de incentivo aos demais municípios que ainda não deram início ao processo de elaboração de seus respectivos planos.

Por fim, cabe ressaltar que para a formação de leitores não basta apenas investir na distribuição de livros, pois a formação integral do leitor crítico e consciente demanda políticas de valorização da biblioteca escolar como ambiente de aprendizagem. Isso exige, além de muita vontade política, urgente e substancial ampliação dos recursos financeiros governamentais de modo a viabilizar o suprimento de carências físicas (construção de ambientes adequados) e humanas (contratação de bibliotecários e capacitação dos demais profissionais) para que seja possível articular os esforços e os resultados pretendidos. Portanto, existe ainda um grande caminho por ser percorrido.

\section{REFERÊNCIAS}

ANDERSON, Perry. Balanço do neoliberalismo. In: SADER, Emir; GENTILI, Pablo (orgs.). Pósneoliberalismo: as políticas sociais e o Estado democrático. Rio de Janeiro: Paz e Terra, 1996. p. 9-23. ANDRÉ, Marli Eliza Dalmazo Afonso de. Estudo de caso em pesquisa e avaliação educacional. Brasília: Liber Livro Editora, 2005.

ANHUMAS. Lei n. 562 de 15 de dezembro de 2016. Institui o Plano Municipal do Livro, Leitura e Literatura - PMLLL, do Município de Anhumas - SP e dá outras providências. Anhumas, 2016.

BIANCHETTT, Roberto Geraldo. Modelo neoliberal e politicas educacionais. São Paulo: Cortez, 1999. 
BORDIGNON, Genuíno. Gestão da educação no município: sistema, conselho e plano. São Paulo: Editora e Livraria Paulo Freire, 2009.

BRASIL. Ministério da Educação. Ministério da Cultura. Caderno do PNLL. ed. at. e rev. Brasília: Ministério da Educação / Ministério da Cultura, 2014. Disponível em http://antigo.cultura.gov.br/pnll. Acesso em 10 out. 2019.

BRASIL. Ministério da Educação. Ministério da Cultura. Guia para elaboração e implantação dos planos estadual e municipal do livro e leitura. Brasília: MEC: MinC, 2015.

BRASIL. Lei n. 12.244, de 24 de maio de 2010. Dispõe sobre a universalização das bibliotecas nas instituições de ensino do País. Planalto: Brasília, 2010. Disponível em www.planalto.gov.br/ccivil_03/_ato2007-2010/2010/lei/112244.html. Acesso em 10 out. 2019.

BRASIL. Lei n. 13.696, de 12 de julho de 2018. Institui a Política Nacional de Leitura e Escrita. Planalto: Brasília, $2018 . \quad$ Disponível em https://presrepublica.jusbrasil.com.br/legislacao/600306209/lei-13696-18. Acesso em 10 out. 2019.

CAMPELLO, Bernadete Santos. História da biblioteca escolar no Brasil: o que sabemos? In: CASTRO, César Augusto; CASTELLANOS, Samuel Luiz Velásquez (orgs.). História da escola: métodos, disciplinas, currículos e espaços de leitura. São Luís: EdUFMA, 2018. p. 467-494.

CRUZ, Priscila; MONTEIRO, Luciano (orgs.). Anuário Brasileiro da Educação Básica - 2019. São Paulo: Moderna, 2019.

DEL ROIO, Marcos. A terceira fase do neoliberalismo. In: LIMA FILHO, Paulo Alves de et al. (orgs.). Setas contra o capital: sobre pandemônios na pandemia e as revoluções necessárias. São Paulo: Aramarani, 2020. p. 225-235.

GADOTTI, Moacir. Perspectivas atuais da educação. Porto Alegre: Artes Médicas, 2000.

GENTILI, Pablo; OLIVEIRA, Dalila Andrade. A procura de igualdade: dez anos de política educacional no Brasil. In: SADER, Emir (org.) 10 anos de governos pós-neoliberais no Brasil: Lula e Dilma. São Paulo: Boitempo, 2013. p. 253-264.

MORAES, Rubens Borba de. Livros e bibliotecas no Brasil Colonial. Brasília: Briquet de Lemos, 2006.

LIBÂNEO, José Carlos; OLIVEIRA, João Ferreira; TOSCHI, Mirza Seabra. Educação escolar: políticas, estrutura e organização. São Paulo: Cortez, 2012.

MUKHINA, Valeria. Psicologia da idade pré-escolar. São Paulo: Martins Fontes, 1996.

PINHEIRO, Ricardo Queiroz. Política pública de leitura e participação social: o processo de construção do PMLLLB de São Paulo. 2016. 209p. Dissertação (Mestrado em Ciência da Informação) - Escola de Comunicações e Artes, Universidade de São Paulo, São Paulo, 2016.

PINTO, José Marcelino de Rezende. Prefácio. In: MILITÃO, Andrea Nunes; PERBONI, Fabio (orgs.). Plano Nacional de Educação: diversos olhares. Curitiba: CRV, 2017, p. 17-18.

POCHMANN, Marcio. Políticas públicas e situação social na primeira década do século XXI. In: SADER, Emir (org.) 10 anos de governos pós-neoliberais no Brasil: Lula e Dilma. São Paulo: Boitempo, 2013. p. 145-156.

RASTELI, Alessandro. Mediação da leitura em bibliotecas públicas. 2013. 169 f. Dissertação (Mestrado em Ciência da Informação) - Faculdade de Filosofia e Ciências, Universidade Estadual Paulista, Marília, 2013.

ROSA, Flávia Goullart Mota Garcia; ODDONE, Nanci. Políticas públicas para o livro, leitura e biblioteca. Ciência da Informaşão, Brasília, v. 35, n. 3, set./dez. 2006. 
SADER, Emir. A construção da hegemonia pós-neoliberal. In: SADER, Emir (org.) 10 anos de governos pós-neoliberais no Brasil: Lula e Dilma. São Paulo: Boitempo, 2013. p. 135-143.

SALA, Fabiana. Politicas públicas do livro, leitura e biblioteca escolar no Brasil: das iniciativas federais à implementação municipal. 2018. 266f. Dissertação (Mestrado em Educação) - Faculdade de Filosofia e Ciências, Universidade Estadual Paulista, Presidente Prudente, 2018.

SAVIANI, Dermeval. Da nova LDB ao FUNDEB: por uma outra política educacional. 2. ed. rev. e ampl. Campinas: Autores Associados, 2008.

SAVIANI, Dermeval. Sistema Nacional de Educação e Regime de Colaboração. In: BRZEZINSKI, Íria (org.). LDB 1996 vinte anos depois: projetos educacionais em disputa. São Paulo: Cortez, 2018. p. 27-46.

SEADE. Perfil municipal. Disponível em http://www.seade.gov.br/produtos/perfil. Acesso em 10 ago. 2018.

SECCHI, Leonardo. Políticas públicas: conceitos, esquemas de análise, casos práticos. São Paulo: Cengage Learning, 2010.

SILVA JUNIOR, João dos Reis; FERRETI, Celso João. O institucional, a organização e a cultura da escola. São Paulo: Xamã, 2004.

Submetido em outubro de 2019

Aprovado em agosto de 2020

\section{Informações dos autores}

Fabiana Sala

Bibliotecária-documentalista do Instituto Federal de Educação, Ciência e Tecnologia de São Paulo IFSP/Presidente Epitácio, Doutoranda do Programa de Pós-Graduação em Ciência da Informação da Universidade Estadual Paulista Júlio de Mesquita Filho - Unesp/Marília.

E-mail: fabianasala@,ifsp.edu.br

ORCID: https://orcid.org/0000-0003-0395-8073

Link Lattes: http://lattes.cnpq.br/1930992539170547

Silvio César Nunes Militão

Professor Doutor do Departamento de Didática da Universidade Estadual Paulista Júlio de Mesquita Filho - Unesp/Marília e docente do Programa de Pós-graduação em Educação da Universidade Estadual Paulista Júlio de Mesquita Filho - Unesp/Presidente Prudente.

E-mail: silvio.militao@unesp.br

ORCID: https://orcid.org/0000-0003-2094-1193

Link Lattes: http://lattes.cnpq.br/0176001395083564 